\title{
Beyond the Raskin Protocol: Ketamine, Lidocaine, and Other Therapies for Refractory Chronic Migraine
}

\author{
Jeffrey J. Mojica ${ }^{1}$ (D) Eric S. Schwenk ${ }^{1}$. Clinton Lauritsen ${ }^{2} \cdot$ Stephanie J. Nahas $^{2}$ \\ Accepted: 29 September 2021 / Published online: 11 December 2021 \\ (c) The Author(s), under exclusive licence to Springer Science+Business Media, LLC, part of Springer Nature 2021
}

\begin{abstract}
Purpose of Review The purpose of this review is to discuss the available evidence and therapeutic considerations for intravenous drug therapy for refractory chronic migraine.

Recent Findings In carefully monitored settings, the inpatient administration of intravenous lidocaine and ketamine can be successful in treating refractory chronic migraine.

Summary Many patients with refractory chronic migraine have experienced treatment failure with the Raskin protocol. The use of aggressive inpatient infusion therapy consisting of intravenous lidocaine or ketamine, along with other adjunctive medications, has become increasingly common for these patients when all other treatments have failed. There is a clear need for prospective studies in this population comprised of patients who have largely been excluded from other studies.
\end{abstract}

Keywords Chronic migraine $\cdot$ Refractory headache $\cdot$ Ketamine $\cdot$ Lidocaine $\cdot$ Raskin protocol

\section{Introduction}

Migraine is one of the most common disabling neurologic conditions. It is a complex neuroinflammatory disorder with a significant genetic basis and is clinically heterogenic in disease severity and symptomatology [1]. In addition to rare monogenic forms of migraine, genome-wide association studies have identified 44 independent single

This article is part of the Topical Collection on Anesthetic Techniques in Pain Management

Jeffrey J. Mojica

jeffrey.mojica@jefferson.edu

Eric S. Schwenk

eric.schwenk@jefferson.edu

Clinton Lauritsen

clinton.lauritsen@jefferson.edu

Stephanie J. Nahas

stephanie.nahas@jefferson.edu

1 Department of Anesthesiology, Sidney Kimmel Medical College at Thomas Jefferson University, 111 South 11th Street, Suite 8290 Gibbon Building, Philadelphia, PA 19107, USA

2 Department of Neurology, Sidney Kimmel Medical College at Thomas Jefferson University, 900 Walnut St., Suite 200, Philadelphia, PA 19107, USA nucleotide polymorphisms associated with migraine risk [2]. The pathophysiology of migraine is complex and is characterized by dysregulation of nociceptive and other sensory processing throughout many central and peripheral modulatory neural structures and networks. This dysregulation is mediated by a variety of neurotransmitters, neuropeptides, and inflammatory molecules [3•]. Variability in the involvement of these etiological factors within individuals is likely a significant contributor to the clinical heterogeneity seen in migraine, including the constellation of symptoms, severity of disease, and response (or lack thereof) to treatments.

With an overall prevalence of about $15 \%$, migraine affects over 1 billion people worldwide and is second on the list of diseases accounting for years lived with disability. In the USA, nearly 40 million children and adults have the disease, and it is the number one cause of years lived with disability for persons aged 15-49 [4]. Migraine can be divided into episodic and chronic forms based on monthly headache frequency cutoff of 15 days per month with at least 8 migraine days per month $[5 \bullet]$. About one in ten patients with migraine has the far more disabling and costly form, chronic migraine $(\mathrm{CM})$, with a global prevalence estimated between 1 and $2 \%$ [6]. A subset of the population of people with CM has extreme disability due to daily or even continuous symptoms despite numerous treatment attempts. 
While there is some disagreement on the precise definition of refractory chronic migraine $(\mathrm{rCM})$, most agree that disabling disease which is unresponsive to $2-4$ classes of commonly used preventive migraine medication qualifies [7]. This cutoff is somewhat arbitrary and may understate the refractory degree of disease, as it is not uncommon for patients to have experienced treatment failure with 20-30 preventive medications [8]. The strictest criteria proposed for rCM have come from the European Headache Federation, which calls for treatment failure with agents from 8 classes of preventive medications including any newly developed therapies [9]. Clinically, there is no specific or consistent symptomatic distinction between $\mathrm{CM}$ and $\mathrm{rCM}$, and risk factors for $\mathrm{rCM}$ are not well established [1]. A major step needed to generate useful data in this population is to establish a widely accepted set of diagnostic criteria. This group of patients is particularly underserved in terms of applicable data from therapeutic trials to guide treatment. Historically, most large randomized controlled trials exclude patients with a history of extensive medication failures, and those who have daily or continuous pain. Trials using aggressive inpatient therapies, including lidocaine and ketamine infusion, are notoriously hard to design ethically with an appropriate control group, as administering a true placebo to such a refractory population would be inappropriate. It is also challenging to blind patients adequately given the prominent and characteristic psychomimetic side effects of ketamine. Thus, our current typical approach to inpatient rCM treatment is largely guided by years of anecdotal experience and observational data.

There are a variety of clinical scenarios in which inpatient treatment for migraine is indicated. In general, these include failure of outpatient management in the setting of status migrainosus or $\mathrm{CM}$ with continuous pain and significant disability, intractable nausea or vomiting, medication overuse headache $(\mathrm{MOH})$, and significant medical or psychiatric comorbidities [10]. While dihydroergotamine (DHE) infusion may be administered safely as an outpatient, the vasoconstrictive properties may make advanced age or cardiovascular comorbidities indications for inpatient treatment for safety reasons $[11,12]$. Inpatients can be monitored on telemetry, and the physician may consult a cardiologist for co-management in patients with substantial risk (Table 1).
Continuous lidocaine infusions can only be administered safely in the inpatient setting. Another complicating factor that may warrant inpatient treatment is the presence of comorbid pain and headache disorders, including fibromyalgia, post-traumatic headache, new daily persistent headache $(\mathrm{NDPH})$, and others [13•].

\section{Historical Background}

For patients with rCM, aggressive interventions are often undertaken, including the use of repetitive doses of intravenous (IV) medications. One of the earliest descriptions of such an approach was detailed and studied by Dr. Neil Raskin and has been dubbed "The Raskin Protocol." A number of "Modified Raskin Protocol" descriptions have followed this, along with the additional use of adjunctive medications.

Raskin's original description from the 1980s [14] detailed the use of repetitive doses of IV DHE and metoclopramide every $8 \mathrm{~h}$ compared to repetitive doses of IV diazepam every $8 \mathrm{~h}$ for up to 2 days in patients with continuous rCM, many of whom had become dependent on analgesics, opioids, ergots, butalbital, benzodiazepines, prednisone, or a combination of those substances. The diazepam group received $10 \mathrm{mg}$ every $8 \mathrm{~h}$. In the DHE group, the dose was adjusted based on the presence of nausea and headache. A "test dose" of $0.5 \mathrm{mg}$ was given initially with $10 \mathrm{mg}$ metoclopramide. If within $1 \mathrm{~h}$ the headache abated or nausea was present, no further doses of DHE were given for $8 \mathrm{~h}$. If nausea recurred with the second dose of DHE $0.5 \mathrm{mg}$ plus metoclopramide $10 \mathrm{mg}$, the dose was reduced to $0.3 \mathrm{mg}$. If after the first dose the headache persisted but there was no nausea at $1 \mathrm{~h}$, another $0.5 \mathrm{mg}$ of DHE was administered, and every $8 \mathrm{~h}$ thereafter for 2 days, $1 \mathrm{mg}$ DHE and $10 \mathrm{mg}$ metoclopramide were given. This was followed by outpatient use of DHE suppositories or injections, as well as propranolol and ergonovine for patients not fully responding to treatment. While non-randomized and unblinded, both treatment groups had similar baseline characteristics, and the DHE group fared far better than the diazepam group, both in the short term and long term, for up to 24 months.

Subsequent to this report, further exploration of the use of repetitive doses of IV DHE for longer periods of time and with alternative adjunctive medications was undertaken by

Table 1 Inpatient infusions for patients with refractory chronic migraine

\begin{tabular}{llll}
\hline Drug & Dosing range & Adverse effects & Select Contraindications and Cautions \\
\hline Dihydroergotamine & $0.1-1 \mathrm{mg} \mathrm{Q8H} \mathrm{SCH}$ & $\begin{array}{c}\text { Nausea/vomiting, hypertension, flushing, diar- } \\
\text { rhea, chest pain, leg cramps }\end{array}$ & $\begin{array}{c}\text { Pregnancy, uncontrolled hypertension, any } \\
\text { active vascular disease }\end{array}$ \\
Ketamine & $0.1-1 \mathrm{mg} / \mathrm{kg} / \mathrm{h}$ continuous & $\begin{array}{c}\text { Hallucinations, nausea/vomiting, sedation, } \\
\text { vivid dreams }\end{array}$ & $\begin{array}{c}\text { Pregnancy, active psychosis, liver disease, } \\
\text { uncontrolled cardiac disease }\end{array}$ \\
Lidocaine & $0.6-4 \mathrm{mg} / \mathrm{min}$ continuous & $\begin{array}{c}\text { Sedation, nausea/vomiting, cardiac dysthyth- } \\
\text { mias, vivid dreams, hallucinations }\end{array}$ & $\begin{array}{c}\text { Certain cardiac rhythm abnormalities such as } \\
\text { heart block or conduction delays }\end{array}$ \\
\hline
\end{tabular}


numerous clinicians and researchers [15]. Alternative neuroleptic medications, such as prochlorperazine, promethazine, droperidol, chlorpromazine, and haloperidol were used instead of metoclopramide, and adjunctive IV medications, such as ketorolac, valproic acid, magnesium, and corticosteroids were also given. In addition, some began to favor scheduling additional "pretreatment" drugs to mitigate side effects, such as utilizing diphenhydramine to prevent neuroleptic-induced akathisia or dystonic reaction. The scientific evidence behind these historical therapies used for decades is weak, owing to the aforementioned challenges of designing randomized, blinded, and controlled studies, and studies using numerous simultaneous medications in a desperate patient population for whom placebo treatment could be viewed as unethical. Still, the available data are promising, and these approaches have been embraced broadly and are still used today, with high levels of satisfaction from patients and clinicians alike.

\section{Intravenous Lidocaine}

\section{Background and Clinical Uses}

Lidocaine is a local anesthetic and antiarrhythmic originally developed in 1943 by Swedish chemists Nils Löfgren and Bengt Lundquist [16]. Prior to its development, the existing lot of local anesthetics were classified as aminoesters. Lidocaine was the first local anesthetic to be classified as an aminoamide. Its rapid onset of action and ease of storage addressed many of the concerns that limited the aminoester class of local anesthetics. The introduction of lidocaine sparked the development of other aminoamides including prilocaine, mepivacaine, bupivacaine, and ropivacaine [17].

Since the 1980s, IV lidocaine has been used for the treatment of various chronic pain conditions. Shortly thereafter, Rosner reported his observations on the efficacy of IV lidocaine in the treatment of headaches [18]. In 1988, Maciewicz et al. was the first group to evaluate the effectiveness of a single bolus dose of IV lidocaine in patients with "vascular headaches" [19]. In their study, a single injection of $100 \mathrm{mg}$ lidocaine was found to produce a rapid, but transient reduction in acute pain in 13 patients with migraine or cluster headache. The mechanism of analgesia was believed to be related to local inhibition of the nociceptive trigeminal afferents that are responsible for nociception [19].

Investigations into the therapeutic potential of IV lidocaine as a continuous infusion have also been studied in various types of headache disorders. Overall, the strength of evidence is weak, and further studies are necessary to confirm their findings.

\section{Evidence for Lidocaine in Headache}

One of the earliest investigations of IV lidocaine infusions was performed by Hand and Stark in 2000 [20]. In their retrospective study, they evaluated 19 patients that received a total of 27 lidocaine infusions. In their study, 22 infusions were given to 18 patients with rebound headache (now called MOH in the diagnostic criteria). The remaining 5 infusions were administered in 3 patients for status migrainosus. Of the 22 infusions for rebound headache, 15 infusions led to successful resolution of headache pain. Partial resolution, which was defined as requiring supplemental DHE, occurred in 3 cases. The remaining 4 infusions provided no relief in patients with rebound headache. In the population of patients receiving lidocaine infusions for status migrainosus, 4 of the 5 infusions successfully relieved the headache [20].

Stark expanded upon his earlier work [20] and, in conjunction with Williams, performed a retrospective review of 71 inpatients admitted for chronic daily headache associated with $\mathrm{MOH}$ [21]. In their study, patients with $\mathrm{MOH}$ were administered $2 \mathrm{mg} / \mathrm{min}$ of an IV lidocaine infusion over a period of 7 to 10 days. According to their protocol, patients were prohibited from taking opioids. Nonsteroidal anti-inflammatory drugs and paracetamol were administered as rescue medications for patients with inadequate relief from the lidocaine infusion. A total of 66 patients completed the full protocol, and $90 \%$ of patients reported an immediate improvement or resolution of their symptoms. Sustained benefits were also observed for $71 \%$ of patients at 6 months; headache was absent in 51\% and improved in $20 \%$ [21].

In a separate retrospective analysis, Rosen et al. analyzed the use of IV lidocaine in 68 patients with chronic daily headache or chronic cluster headache [22]. Unlike the previously described studies, the lidocaine infusion was titrated to a serum concentration of less than $5 \mu \mathrm{g} /$ $\mathrm{mL}$. The duration of therapy ranged from 2 to 15 days (mean 8.5 days). Headache severity was measured on an 11-point verbal rating scale, with a score of 0 indicating headache freedom and a score of 10 indicating the worst possible headache. A mean 4-point reduction in headache intensity $(p<0.001)$ was observed following IV lidocaine therapy. Complete $(25.4 \%)$ or partial $(57.1 \%)$ resolution of headache symptoms occurred in a substantial proportion of patients. Interestingly, serum lidocaine levels did not correlate with improvement [22]. Mexiletine, an oral sodium channel antagonist with limited evidence for use in refractory headache prevention, may be administered daily following successful inpatient infusion with lidocaine in attempt to prolong the improvement achieved with hospitalization [23]. 


\section{Mechanism of Action in Headache}

Despite demonstrating analgesic efficacy for various acute and chronic pain states, the exact mechanism in which IV lidocaine produces analgesia is not clear. Best known for its ability to block voltage gated sodium channels (VGSCs), this is unlikely to be the mechanism for headache relief. Lidocaine appears to interact with several other molecular targets, including potassium channels, calcium channels, G-protein-coupled receptors, acetylcholine receptors, gamma-aminobutyric acid receptors (GABA), serotonin receptors, $\mathrm{N}$-methyl-D-aspartate (NMDA) receptors, and toll-like receptors [24]. Many of these receptors are implicated in the induction, maintenance, and modulation of chronic pain states. Serotonin and GABA receptors, for example, are involved in the descending inhibition of pain [25]. Lidocaine's interaction with second messenger systems and cell-signaling cascades may explain the clinical effects that persist well beyond its short plasma half-life of 90-120 min [24].

The analgesic benefits of lidocaine also may be mediated indirectly via its primary metabolite, monoethylglycine (MEG) $[24,26]$. Animal models suggest that MEG attenuates the inflammatory pain response and indirectly regulates the extracellular glycine concentration via competitive inhibition of the glycine transporter, GlyT1 [26]. Glycine is a major neurotransmitter involved in the descending regulation of pain $[25,26]$.

An alternative explanation of lidocaine's analgesic effects pertains to its anti-inflammatory properties [24, 27]. Preclinical and clinical studies demonstrate that lidocaine attenuates the neuroinflammatory response involved in the induction and maintenance of chronic pain states [28].

In summary, the anti-nociceptive mechanisms of IV lidocaine in headache are complex and not well understood, but central mechanisms involved with the modulation of pain and other neuroinflammatory processes are believed to be key.

\section{Adverse Effects}

The short half-life and favorable pharmacokinetic profile of IV lidocaine make it relatively safe for continuous IV delivery $[29,30]$. However, local anesthetic systemic toxicity (LAST) can occur if plasma lidocaine concentrations exceed $5 \mu \mathrm{g} / \mathrm{ml}$ [29]. IV lidocaine preferentially distributes to the organs with the greatest perfusion, such as the brain and heart [31]. This distribution pattern explains why the adverse effects of LAST are central nervous system (CNS) and cardiovascular (CV) in origin. Symptom severity ranges from mild CNS phenomena (perioral numbness, metallic taste in the mouth, lightheadedness, and tinnitus) and mild
$\mathrm{CV}$ manifestations (hypertension and tachycardia) to complete CNS and CV collapse [32].

Adverse CV effects are much less common, but cardiac arrest was reported in a 52-year-old woman receiving IV lidocaine for intractable hemicrania continua [33]. In this case report, the authors hypothesized that the concomitant use of sertraline and trazodone, which are competitive inhibitors of the CYP3A4 enzyme, led to accumulation and a plasma lidocaine level of $16 \mu \mathrm{g} / \mathrm{mL}$ [33]. Drug accumulation can also occur in patients with hepatic or renal insufficiency. Propranolol, used commonly for migraine prevention, also can lead to inhibition of hepatic metabolism and subsequently toxic lidocaine levels [34]. Frequent measurements of plasma lidocaine levels can be performed to ensure that plasma lidocaine levels remain within the therapeutic range of $2-5 \mu \mathrm{g} / \mathrm{mL}$ [29].

\section{Subanesthetic Ketamine}

\section{Background and Clinical Uses}

With the worsening of the opioid crisis during the COVID19 pandemic [35], pharmacological alternatives to opioids for acute and chronic pain are needed more than ever. One of the agents that has received great attention is ketamine, perhaps best known as a dissociative anesthetic agent. This description was initially used in the first report of ketamine in humans by Domino et al. in 1965 [36] and refers to the phenomenon that the frontal cortex is stimulated while other areas, such as the thalamus, are suppressed, resulting in a "dissociation" between various parts of the brain [37]. Ketamine is well known as a non-competitive antagonist of the NMDA receptor, which is thought to be responsible for many of its effects in acute and chronic pain, though multiple other mechanisms of action contribute [38]. For postoperative pain and in opioid-tolerant patients undergoing surgery, ketamine has been recommended by national guidelines as an adjunct to opioids to improve analgesia and reduce overall opioid consumption [39]. Ketamine has been shown to produce short- and medium-term pain relief in complex regional pain syndrome [40, 41], a chronic pain condition recently categorized as nociplastic pain [42]. Nociplastic pain refers to disorders that involve altered pain processing but do not conform to the nociceptive pain definition and lack a distinct nerve injury that would qualify them as neuropathic pain [43].

\section{Evidence for Ketamine in Headache}

Several studies that have evaluated ketamine's effects in various headache conditions have come from the emergency department (ED) setting, but few studies have focused on 
ketamine for refractory headache. In one clinical trial that compared intranasal (IN) ketamine to IV metoclopramide in patients presenting to the ED with a primary complaint of headache, IN ketamine was not found to be superior to metoclopramide at $30 \mathrm{~min}$ after administration [44]. In another randomized controlled trial, a single infusion of $0.2 \mathrm{mg} / \mathrm{kg}$ of IV ketamine in the ED did not reduce acute migraine symptoms compared to placebo [45]. In one review, the authors stated that "ketamine... does not provide substantial relief to migraine patients" [46]. However, their claim was based on the results of two studies limited to acute migraine in the ED.

To the contrary, studies that have focused on patients with $\mathrm{CM}$ or more severe disease have found mostly positive results. In a double-blind, randomized controlled trial, Afridi et al. compared IN ketamine to IN midazolam for migraine with prolonged aura and found that ketamine reduced the severity of the aura [47]. One small case series of 6 patients with $\mathrm{rCM}$ reported short-term relief after a continuous multi-day ketamine infusion [48]. A retrospective study of 77 patients with CM or NDPH concluded that $71.4 \%$ of patients with refractory headache reported short-term response after a multi-day continuous ketamine infusion, though the sustained response was not statistically significant [49]. A subsequent study from the same institution that included 61 patients with refractory headache reported that $77 \%$ were short-term responders after a 5-day ketamine infusion, with less than half maintaining that level of relief at 1 and 3 months [13•]. Possible explanations for the inconsistent results in acute versus refractory migraine are discussed in the next section.

\section{Mechanism of Action in Headache}

While the involvement of the NMDA receptor in ketamine's anesthetic and acute pain action is established [38], the positive results observed in studies in CM may point to the involvement of additional mechanisms of action. Studies performed in the ED have used a single, low-dose infusion and assessed analgesia almost immediately after the infusion. In the ED, where preventing unnecessary hospital admissions is an important goal and short-term analgesia is the focus, ketamine appears to provide minimal benefit in the acute setting [46]. However, in CM, where symptoms are more frequent and disabling [5•], the goal of treatment is often improving quality of life and functionality over the long term and "breaking the cycle" of continual pain. In the studies analyzed above that included patients with CM, longer infusions at greater doses were used to achieve better results. In the study by Schwenk et al. [13•], the mean maximum ketamine infusion rate was $0.76 \mathrm{mg} / \mathrm{kg}$ per hour, which is substantially higher than the doses used in the ED studies [44, 45], and more importantly, the infusions were continued for 5 days. Sustained relief was achieved in some of the patients, although these findings should be interpreted cautiously given the lack of a standardized post-discharge medication regimen. Guidelines on the use of ketamine infusions for chronic pain from the American Society of Regional Anesthesia and Pain Medicine state that duration of clinical benefit has been associated with the total ketamine dose administered [38], which is consistent with the findings observed in headache patients as well.

One possible explanation for the positive results seen in $\mathrm{CM}$ with ketamine is that during longer infusions, the plasma levels of key ketamine metabolites accumulate and might contribute to analgesia. In particular, $(2 \mathrm{R}, 6 \mathrm{R})$ hydroxynorketamine has been shown to be the predominant metabolite after 3 days of continuous ketamine in a patient with complex regional pain syndrome [50]. (2R,6R)Hydroxynorketamine has exhibited analgesic properties in a preclinical study in several models of pain [51]. While larger studies in humans are clearly needed, and no definitive statements can be made, these findings together raise the possibility that in certain chronic disease states such as $\mathrm{rCM}$, the benefits are greatest when ketamine infusions are given for several days at a time at the highest doses tolerated.

One additional possibility worth noting is that ketamine could be exerting anti-inflammatory effects in rCM. Modern hypotheses about the pathophysiology of migraine include the assumption that neurogenic inflammation contributes to symptoms [52]. This assumption has partially provided the basis for the introduction of the calcitonin gene-related peptide inhibitors as a novel class of migraine drugs [53]. One study in treatment-resistant depression examined the correlation between the antidepressant effect of a low-dose ketamine infusion and pro-inflammatory markers, including C-reactive protein, interleukin-6, and tumor necrosis factoralpha, and found that ketamine was associated with a reduction in cytokine levels [54]. However, studies examining ketamine's effects on inflammatory markers in depression have been inconsistent overall [55], and while some authors have suggested it could reduce inflammation in painful states [56], the clinical correlates of these hypotheses are lacking.

\section{Exploring Novel Ketamine Mechanisms}

Ketamine use has been shown to result in neuroplasticity and neurogenesis, demonstrating lasting structural and functional neurological changes. Ketamine use in treatment-resistant depression resulted in rapid changes in white matter diffusivity and microstructure [57]. In this population, a single dose of ketamine has been shown to produce rapid relief of symptoms that lasts up to 2 weeks [58]. Another rapid effect observed from ketamine administration is induction of hippocampal neuron maturation [59]. Ketamine has been shown to increase brain-derived neurotrophic factor resulting in 
functional connectivity changes within the brain [60]. Ketamine may also exert anti-nociceptive activity through direct activity on $\mu$ - and $\delta$-opioid receptors and by induction of endogenous opioid synthesis [61]. Finally, in addition to NMDA receptor activity, ketamine's anti-nociceptive effect is associated with increased $\alpha$-amino-3-hydroxy-5-methyl4-isoxazolepropionic acid receptor (also known as AMPAR) activity and enhanced serotonergic neurotransmission [62].

At this time, definitive anti-nociceptive mechanisms of ketamine are not fully established, and the primary mechanisms at play in patients with migraine remain speculative. Future studies will be required to further elucidate this.

\section{Adverse Effects}

Ketamine is associated with a variety of adverse effects, most of which have been reported as mild in clinical studies but which can require adjustment in infusion rate or treatment with adjunctive medications. One meta-analysis of subanesthetic perioperative ketamine found that the incidence of psychomimetic effects (hallucinations, psychiatric disturbances, unpleasant dreams, diplopia, blurred vision, nystagmus, or dysphoria) was increased in patients who received ketamine versus control groups [63], while another found that psychomimetic effects were equal in ketamine and control groups [64]. However, when looking specifically at patients receiving ketamine for headache, one report noted that hallucinations occurred in $28 \%$ of patients, vivid dreams in $13 \%$, blurry vision in $38 \%$, and nausea and vomiting in $38 \%$ [13•]. In that study, the mean maximum ketamine infusion rate was $0.76 \mathrm{mg} / \mathrm{kg}$ per hour, and all patients received a clonidine patch to mitigate adverse effects. Clonidine is also useful in mitigating the sympathomimetic effects of ketamine such as hypertension [65], as well as insomnia and agitation. The authors reported that 60 of the 61 patients completed their 5-day treatment course with 1 patient electing to stop because of adverse effects. These results are somewhat difficult to interpret because patients with $\mathrm{CM}$ often report nausea and vomiting as part of their clinical syndrome [66] and patients in this study were also given neuroleptic medications that could have caused some of the psychomimetic effects. For patients with psychiatric comorbidities, such as depression, post-traumatic stress disorder, bipolar disorder, dissociative disorders, or suicidal ideation, co-management with a psychiatrist should be considered. In general, ketamine's adverse effects occur when infusions are given for prolonged periods of time and at higher doses. Mitigating medications, such as clonidine [67] and benzodiazepines [68], can help reduce duration and severity of these effects but cannot fully prevent them.

Ketamine use, especially chronic abuse, may result in end organ damage, including liver and bladder toxicity. Ketamine-induced cystitis is thought to occur due to direct toxicity and induction of apoptosis in urothelial cells [69]. Papillary necrosis can lead to ureteral obstruction, urinary retention, and hemorrhagic cystitis [70]. Patients should be monitored for the development of urinary symptoms. National guidelines for the use of ketamine have recommended that ketamine be avoided in patients with severe liver disease and used cautiously in patients with moderate disease [38]. Furthermore, the guidelines state that liver toxicity most commonly presents as elevated liver transaminases and mostly has been observed in ketamine abusers. However, a subsequent report of 115 patients with $\mathrm{rCM}$ and complex regional pain syndrome found that patients were more likely to have developed elevated transaminases during a repeat ketamine infusion than their initial infusion [71], so caution is warranted even with medically supervised ketamine infusions, and consideration of liver function tests should be given when high-dose or multi-day infusions are planned.

A variety of concerns about potentially deleterious effects of ketamine stem from data in patients chronically abusing the drug. Studies have identified long-term effects, including focal decrease in brain connectivity, focal decrease in cortical volumes, impairment within certain cognitive domains, and white matter changes [72-74]. However, there are several confounding variables in these studies, and it is not possible to establish causality or implications of the findings from this relatively weak evidence. Large controlled longitudinal studies are required to further evaluate the long-term effects of ketamine.

\section{Conclusion}

Migraine remains tremendously burdensome, especially for the small yet substantial proportion of patients with extremely refractory disease. For nearly 30 years, dedicated advanced treatment approaches have been explored with a goal of providing meaningful relief. Despite advances to date, there remain far too many patients who continue to experience treatment failure from very aggressive, and in some cases risky, combination approaches. Most, if not all, patients with rCM have experienced failure with the Raskin protocol when used without the co-administration of multiple other infusions. Thus, a modified, multiday, aggressive inpatient infusion approach has become increasingly common for $\mathrm{rCM}$ and incorporates a variety of other medications, including co-administration with continuous lidocaine or ketamine infusions in a closely monitored setting to mitigate serious adverse events. A widely accepted standardized set of criteria for $\mathrm{rCM}$ diagnosis is needed to further explore the unique demographics, pathophysiological mechanisms, risk factors, and prognostic factors for $\mathrm{rCM}$. This will facilitate the future research that is required to identify more 
effective, safe, and tailored therapeutic approaches to better complement a holistic, multidisciplinary plan of care.

\section{Compliance with Ethical Standards}

Conflict of Interest The authors declare no competing interests.

Human and Animal Rights and Informed Consent This article does not contain any studies with human or animal subjects performed by any of the authors.

\section{References}

Papers of particular interest, published recently, have been highlighted as:

\section{- Of importance}

1. Goadsby PJ, Hargreaves R. Refractory migraine and chronic migraine: pathophysiological mechanisms. Headache. 2008;48(9):1399-405. https://doi.org/10.1111/j.1526-4610. 2008.01274.x.

2. Gormley P, Anttila V, Winsvold BS, Palta P, Esko T, Pers TH, et al. Meta-analysis of 375,000 individuals identifies 38 susceptibility loci for migraine. Nat Genet. 2016;48(8):856-66. https:// doi.org/10.1038/ng.3598.

3. Goadsby PJ, Holland PR. An update: pathophysiology of migraine. Neurol Clin. 2019;37(4):651-71.https://doi.org/10. $1016 /$ j.ncl.2019.07.008. Useful article for providing understanding of migraine mechanisms.

4. Vos T, Abajobir AA, Abate KH, Abbafati C, Abbas KM, AbdAllah F, et al. Global, regional, and national incidence, prevalence, and years lived with disability for 328 diseases and injuries for 195 countries, 1990-2016: a systematic analysis for the Global Burden of Disease Study 2016. The Lancet. 2017;390(10100):1211-59. https://doi.org/10.1016/s0140-6736(17)32154-2.

5. Headache Classification Committee of the International Headache Society (IHS). The International Classification of Headache Disorders, 3rd edition. Cephalalgia. 2018;38(1):1-211. https://doi.org/10.1177/0333102417738202. Important definition of chronic migraine described here.

6. Natoli JL, Manack A, Dean B, Butler Q, Turkel CC, Stovner $\mathrm{L}$, et al. Global prevalence of chronic migraine: a systematic review. Cephalalgia. 2010;30(5):599-609. https://doi.org/10. 1111/j.1468-2982.2009.01941.x.

7. Schulman EA, Lake AE 3rd, Goadsby PJ, Peterlin BL, Siegel SE, Markley HG, et al. Defining refractory migraine and refractory chronic migraine: proposed criteria from the Refractory Headache Special Interest Section of the American Headache Society. Headache. 2008;48(6):778-82. https://doi.org/10.1111/j.1526-4610. 2008.01132.x.

8. Lauritsen C, Mazuera S, Lipton RB, Ashina S. Intravenous ketamine for subacute treatment of refractory chronic migraine: a case series. J Headache Pain. 2016;17(1):106. https://doi.org/ 10.1186/s10194-016-0700-3.

9. Sacco S, Braschinsky M, Ducros A, Lampl C, Little P, van den Brink AM, et al. European headache federation consensus on the definition of resistant and refractory migraine : Developed with the endorsement of the European Migraine \& Headache Alliance (EMHA). J Headache Pain. 2020;21(1):76. https://doi. org/10.1186/s10194-020-01130-5.
10. Marmura MJ, Hou A. Inpatient management of migraine. Neurol Clin. 2019;37(4):771-88. https://doi.org/10.1016/j.ncl.2019.07. 007.

11. Khalife J, Lauritsen CG, Liang J, Shah SO. DHE-induced peripheral arterial vasospasm in primary Raynaud phenomenon: case report. Neurohospitalist. 2019;9(2):113-5. https://doi.org/ $10.1177 / 1941874418797764$

12. Lauritsen C, Myers M, Hopkins M, Silberstein S. Safety and efficacy of repetitive dihydroergotamine infusion for the acute treatment of refractory chronic migraine in hospitalized patients with vascular risk factors (4366). Neurology. 2021;96(15 Supplement):4366.

13. Schwenk ES, Dayan AC, Rangavajjula A, Torjman MC, Hernandez MG, Lauritsen CG et al. Ketamine for refractory headache: a retrospective analysis. Reg Anesth Pain Med. 2018;43(8):8759.https://doi.org/10.1097/AAP.0000000000000827. One of the only studies of subanesthetic ketamine for refractory headache.

14. Raskin NH. Repetitive intravenous dihydroergotamine as therapy for intractable migraine. Neurology. 1986;36(7):995. https://doi. org/10.1212/wnl.36.7.995.

15. Robblee J, Grimsrud KW. Emergency department and inpatient management of headache in adults. Curr Neurol Neurosci Rep. 2020;20(4). https://doi.org/10.1007/s11910-020-01030-w.

16. Gordh T. Xylocain, a new local analgesic. Anaesthesia. 1949;4(1):4 9. https://doi.org/10.1111/j.1365-2044.1949.tb05802.x.

17. Gordh T, Gordh TE, Lindqvist K. Lidocaine: the origin of a modern local anesthetic. Anesthesiology. 2010;113(6):1433-7. https://doi.org/10.1097/aln.0b013e3181fcef48.

18. Rosner S. A simple method of treatment for the acute headache. Headache. 1984;24(1):50.

19. Maciewicz R, Chung RY, Strassman A, Hochberg F, Moskowitz M. Relief of vascular headache with intravenous lidocaine: clinical observations and a proposed mechanism. Clin J Pain. 1988;4(1):11-6.

20. Hand PJ, Stark RJ. Intravenous lignocaine infusions for severe chronic daily headache. Med J Aust. 2000;172(4):157-9. https:// doi.org/10.5694/j.1326-5377.2000.tb125538.x.

21. Williams D, Stark R. Intravenous Lignocaine (Lidocaine) Infusion for the treatment of chronic daily headache with substantial medication overuse. Cephalalgia. 2003;23(10):963-71. https:// doi.org/10.1046/j.1468-2982.2003.00623.x.

22. Rosen N, Marmura M, Abbas M, Silberstein S. Intravenous lidocaine in the treatment of refractory headache: a retrospective case series. Headache. 2009;49(2):286-91. https://doi.org/10. 1111/j.1526-4610.2008.01281.x.

23. Marmura MJ, Passero FC Jr, Young WB. Mexiletine for refractory chronic daily headache: a report of nine cases. Headache. 2008;48(10):1506-10. https://doi.org/10.1111/j.1526-4610.2008. 01234.x.

24. Hermanns H, Hollmann MW, Stevens MF, Lirk P, Brandenburger $\mathrm{T}$, Piegeler T, et al. Molecular mechanisms of action of systemic lidocaine in acute and chronic pain: a narrative review. $\mathrm{Br} \mathrm{J}$ Anaesth. 2019;123(3):335-49. https://doi.org/10.1016/j.bja.2019.06.014.

25. Almeida TF, Roizenblatt S, Tufik S. Afferent pain pathways: a neuroanatomical review. Brain Res. 2004;1000(1-2):40-56. https://doi.org/10.1016/j.brainres.2003.10.073.

26. Berk T, Silberstein SD. The use and method of action of intravenous lidocaine and its metabolite in headache disorders. Headache. 2018;58(5):783-9. https://doi.org/10.1111/head.13298.

27. Hollmann MW, Durieux ME, Fisher DM. Local anesthetics and the inflammatory response. Anesthesiology. 2000;93(3):858-75. https://doi.org/10.1097/00000542-200009000-00038.

28. Ji R-R, Nackley A, Huh Y, Terrando N, Maixner W. Neuroinflammation and central sensitization in chronic and widespread pain. Anesthesiology. 2018;129(2):343-66. https://doi.org/10. 1097/aln.0000000000002130. 
29. Eipe N, Gupta S, Penning J. Intravenous lidocaine for acute pain: an evidence-based clinical update. BJA Education. 2016;16(9):292-8. https://doi.org/10.1093/bjaed/mkw008.

30. Weibel S, Jelting Y, Pace NL, Helf A, Eberhart LH, Hahnenkamp $\mathrm{K}$, et al. Continuous intravenous perioperative lidocaine infusion for postoperative pain and recovery in adults. Cochrane Database Syst Rev. 2018. https://doi.org/10.1002/14651858.cd009642.pub3.

31. Tucker GT, Mather LE. Pharmacology of local anaesthetic agents. Pharmacokinetics of local anaesthetic agents. Br J Anaesth. 1975;47:213-24.

32. Neal JM. Ultrasound-guided regional anesthesia and patient safety: update of an evidence-based analysis. Reg Anesth Pain Med. 2016;41(2):195-204. https://doi.org/10.1097/AAP. 0000000000000295.

33. Digala LP, Lucchese S. IV Lidocaine infusion leading to the toxic levels in serum causing asystole - a case report. Headache. 2020;60(1):269-70. https://doi.org/10.1111/head.13699.

34. Branch RA, Shand DG, Wilkinson GR, Nies AS. The reduction of lidocaine clearance by dl-propranolol: an example of hemodynamic drug interaction. J Pharmacol Exp Ther. 1973;184(2):515-9.

35. Silva MJ, Kelly Z. The escalation of the opioid epidemic due to COVID-19 and resulting lessons about treatment alternatives. Am J Manag Care. 2020;26(7):e202-4. https://doi.org/10.37765/ajmc. 2020.43386.

36. Domino EF, Chodoff P, Corssen G. Pharmacologic effects of CI-581, a new dissociative anesthetic, in man. Clin Pharmacol Ther. 1965;6:279-91. https://doi.org/10.1002/cpt196563279.

37. Corssen G, Miyasaka M, Domino EF. Changing concepts in pain control during surgery: dissociative anesthesia with CI-581. A progress report Anesth Analg. 1968;47(6):746-59.

38. Cohen SP, Bhatia A, Buvanendran A, Schwenk ES, Wasan AD, Hurley RW, et al. Consensus guidelines on the use of intravenous ketamine infusions for chronic pain from the American Society of Regional Anesthesia and Pain Medicine, the American Academy of Pain Medicine, and the American Society of Anesthesiologists. Reg Anesth Pain Med. 2018;43(5):521-46. https://doi. org/10.1097/AAP.0000000000000808.

39. Schwenk ES, Viscusi ER, Buvanendran A, Hurley RW, Wasan $\mathrm{AD}$, Narouze $\mathrm{S}$, et al. Consensus guidelines on the use of intravenous ketamine infusions for acute pain management from the American Society of Regional Anesthesia and Pain Medicine, the American Academy of Pain Medicine, and the American Society of Anesthesiologists. Reg Anesth Pain Med. 2018;43(5):456-66. https://doi.org/10.1097/AAP.0000000000000806.

40. Sigtermans MJ, van Hilten JJ, Bauer MC, Arbous MS, Marinus J, Sarton EY, et al. Ketamine produces effective and long-term pain relief in patients with Complex Regional Pain Syndrome Type 1. Pain. 2009;145:304-11.

41. Schwartzman RJ, Alexander GM, Grothusen JR, Paylor T, Reichenberger E, Perreault M. Outpatient intravenous ketamine for the treatment of complex regional pain syndrome: a doubleblind placebo controlled study. Pain. 2009;147(1-3):107-15. https://doi.org/10.1016/j.pain.2009.08.015.

42. Popkirov S, Enax-Krumova EK, Mainka T, Hoheisel M, Hausteiner-Wiehle C. Functional pain disorders - more than nociplastic pain. NeuroRehabilitation. 2020;47(3):343-53. https://doi.org/10.3233/nre-208007.

43. Orhurhu V, Orhurhu MS, Bhatia A, Cohen SP. Ketamine infusions for chronic pain: a systematic review and meta-analysis of randomized controlled trials. Anesth Analg. 2019;129(1):24154. https://doi.org/10.1213/ane.0000000000004185.

44. Benish T, Villalobos D, Love S, Casmaer M, Hunter CJ, Summers SM, et al. The THINK (Treatment of Headache with Intranasal Ketamine) Trial: a randomized controlled trial comparing intranasal ketamine with intravenous metoclopramide. J Emerg Med.
2019;56(3):248-57. https://doi.org/10.1016/j.jemermed.2018.12. 007.

45. Etchison AR, Bos L, Ray M, McAllister KB, Mohammed M, Park B, et al. Low-dose ketamine does not improve migraine in the emergency department: a randomized placebo-controlled trial. West J Emerg Med. 2018;19(6):952-60. https://doi.org/ 10.5811/westjem.2018.8.37875.

46. Naeem F, Schramm C, Friedman BW. Emergent management of primary headache: a review of current literature. Curr Opin Neurol. 2018;31(3):286-90. https://doi.org/10.1097/wco. 0000000000000547.

47. Afridi SK, Giffin NJ, Kaube H, Goadsby PJ. A randomized controlled trial of intranasal ketamine in migraine with prolonged aura. Neurology. 2013;80:642-7.

48. Lauritsen C, Mazuera S, Lipton RB, Ashina S. Intravenous ketamine for subacute treatment of refractory chronic migraine: a case series. J Headache Pain. 2016;17(106). https://doi.org/ 10.1186/s10194-016-0700-3.

49. Pomeroy JL, Marmura MJ, Nahas SJ, Viscusi ER. Ketamine infusions for treatment refractory headache. Headache. 2017;57(2):27682. https://doi.org/10.1111/head.13013.

50. Moaddel R, Venkata SL, Tanga MJ, Bupp JE, Green CE, Iyer L, et al. A parallel chiral-achiral liquid chromatographic method for the determination of the stereoisomers of ketamine and ketamine metabolites in the plasma and urine of patients with complex regional pain syndrome. Talanta. 2010;82(5):1892-904. https:// doi.org/10.1016/j.talanta.2010.08.005.

51. Kroin JS, Das V, Moric M, Buvanendran A. Efficacy of the ketamine metabolite $(2 \mathrm{R}, 6 \mathrm{R})$-hydroxynorketamine in mice models of pain. Reg Anesth Pain Med. 2019;44(1):111-7. https://doi. org/10.1136/rapm-2018-000013.

52. Lukacs M, Tajti J, Fulop F, Toldi J, Edvinsson L, Vecsei L. Migraine, neurogenic inflammation, drug development pharmacochemical aspects. Curr Med Chem. 2017;24(33):3649-65. https://doi.org/10.2174/0929867324666170712163437.

53. Urits I, Jones MR, Gress K, Charipova K, Fiocchi J, Kaye AD, et al. CGRP antagonists for the treatment of chronic migraines: a comprehensive review. Curr Pain Headache Rep. 2019;23(5):29. https://doi.org/10.1007/s11916-019-0768-y.

54. Chen MH, Li CT, Lin WC, Hong CJ, Tu PC, Bai YM, et al. Rapid inflammation modulation and antidepressant efficacy of a low-dose ketamine infusion in treatment-resistant depression: a randomized, double-blind control study. Psychiatry Res. 2018;269:207-11. https://doi.org/10.1016/j.psychres.2018.08.078.

55. Cui W, Ning Y, Hong W, Wang J, Liu Z, Li MD. Crosstalk between inflammation and glutamate system in depression: signaling pathway and molecular biomarkers for ketamine's antidepressant effect. Mol Neurobiol. 2019;56(5):3484-500. https:// doi.org/10.1007/s12035-018-1306-3.

56. De Kock M, Loix S, Lavand'homme P. Ketamine and peripheral inflammation. CNS Neurosci Ther. 2013;19(6):403-10. https:// doi.org/10.1111/cns.12104.

57. Sydnor VJ, Lyall AE, Cetin-Karayumak S, Cheung JC, Felicione JM, Akeju O, et al. Studying pre-treatment and ketamine-induced changes in white matter microstructure in the context of ketamine's antidepressant effects. Transl Psychiatry. 2020;10(1):432. https://doi.org/10.1038/s41398-020-01122-8.

58. Corriger A, Pickering G. Ketamine and depression: a narrative review. Drug Des Devel Ther. 2019;13:3051-67. https://doi.org/ $10.2147 /$ dddt.S221437.

59. Soumier A, Carter RM, Schoenfeld TJ, Cameron HA. New hippocampal neurons mature rapidly in response to ketamine but are not required for its acute antidepressant effects on neophagia in rats. eNeuro. 2016;3(2). https://doi.org/10.1523/eneuro.0116-15. 2016. 
60. Woelfer M, Li M, Colic L, Liebe T, Di X, Biswal B, et al. Ketamineinduced changes in plasma brain-derived neurotrophic factor (BDNF) levels are associated with the resting-state functional connectivity of the prefrontal cortex. World J Biol Psychiatry. 2020;21(9):696-710. https://doi.org/10.1080/15622975.2019.1679391.

61. Petrocchi JA, de Almeida DL, Paiva-Lima P, Queiroz-Junior C, Caliari MV, Duarte IDG, et al. Peripheral antinociception induced by ketamine is mediated by the endogenous opioid system. Eur J Pharmacol. 2019;865: 172808. https://doi.org/10. 1016/j.ejphar.2019.172808.

62. Erdinc M, Uyar E, Kelle I, Akkoc H. Anti-nociceptive effects of low dose ketamine in mice may be mediated by the serotonergic systems. Psychiatr Clin Psychopharmacol. 2019;29(3):252-6. https://doi.org/10.1080/24750573.2019.1605665.

63. Laskowski K, Stirling A, McKay WP, Lim HJ. A systematic review of intravenous ketamine for postoperative analgesia. Can J Anaesth. 2011;58(10):911-23. https://doi.org/10.1007/ s12630-011-9560-0.

64. Jouguelet-Lacoste J, LaColla L, Schilling D, Chelly JE. The use of intravenous infusion or single dose of low-dose ketamine for postoperative analgesia: a review of the current literature. Pain Med. 2015;16:383-403.

65. Riva-Posse P, Reiff CM, Edwards JA, Job GP, Galendez GC, Garlow SJ, et al. Blood pressure safety of subanesthetic ketamine for depression: a report on 684 infusions. J Affect Disord. 2018;236:291-7. https://doi.org/10.1016/j.jad.2018.02.025.

66. Schwedt TJ. Chronic migraine. BMJ. 2014;348:g1416. https:// doi.org/10.1136/bmj.g1416.

67. Handa F, Tanaka M, Nishikawa T, Toyooka H. Effects of oral clonidine premedication on side effects of intravenous ketamine anesthesia: a randomized, double-blind, placebo-controlled study. J Clin Anesth. 2000;12(1):19-24. https://doi.org/10.1016/ s0952-8180(99)00131-2.

68. Elia N, Tramèr MR. Ketamine and postoperative pain-a quantitative systematic review of randomised trials. Pain. 2005;113(1-2):61-70. https://doi.org/10.1016/j.pain.2004.09.036.

69. Baker SC, Shabir S, Georgopoulos NT, Southgate J. Ketamineinduced apoptosis in normal human urothelial cells: a direct, $\mathrm{N}$-methyl-d-aspartate receptor-independent pathway characterized by mitochondrial stress. Am J Pathol. 2016;186(5):126777. https://doi.org/10.1016/j.ajpath.2015.12.014.

70. Srirangam S, Mercer J. Ketamine bladder syndrome: an important differential diagnosis when assessing a patient with persistent lower urinary tract symptoms. BMJ Case Rep. 2012;2012. https://doi.org/10.1136/bcr-2012-006447.

71. Mendelson AM, Kohan L, Okai J, Wanees M, Gonnella JC, Torjman MC, et al. Adverse drug effects related to multiday ketamine infusions: multicenter study. Reg Anesth Pain Med. 2020. https://doi.org/10.1136/rapm-2019-101173.

72. Zhang C, Xu Y, Zhang B, Hao W, Tang WK. Cognitive impairment in chronic ketamine abusers. Psychiatry Res. 2020;291: 113206. https://doi.org/10.1016/j.psychres.2020.113206.

73. Hung CC, Zhang S, Chen CM, Duann JR, Lin CP, Lee TS, et al. Striatal functional connectivity in chronic ketamine users: a pilot study. Am J Drug Alcohol Abuse. 2020;46(1):31-43. https://doi. org/10.1080/00952990.2019.1624764.

74. Zhong J, Wu H, Wu F, He H, Zhang Z, Huang J, et al. Cortical thickness changes in chronic ketamine users. Front Psychiatry. 2021;12:645471. https://doi.org/10.3389/fpsyt.2021.645471.

Publisher's Note Springer Nature remains neutral with regard to jurisdictional claims in published maps and institutional affiliations. 